FROM THE THIRD GENEVA CONFERENCE ON PERSON-CENTERED MEDICINE: SPECIAL INITIATIVES FOR PERSON-CENTERED CARE

\title{
Person-centered Medicine and the Perspective of the International Federation of Gynaecology and Obstetrics - the example of screening for chromosomal abnormalities in pregnancy
}

\author{
Wolfgang Holzgreve MD MBA DSc FACOG FRCOG ${ }^{a}$ and Gamal I. Serour MD FRCS \\ FRCOG
}

a Honorary Treasurer, International Federation of Gynaecology and Obstetrics (FIGO), Berlin, Germany b President, International Federation of Gynaecology and Obstetrics (FIGO), Cairo, Egypt

\begin{abstract}
The International Federation of Gynaecology and Obstetrics (FIGO: www.figo.org) which has member societies in 124 countries/territories across five regions, supports the concept of Person-centered Medicine, because our global organization shares the value of person- and people-centeredness, ethical aspirations, communication skills and respect for cultural diversity. In this article, first some general statements about the mission of FIGO, its aims, organizational structure and current activities are made and then a current example of Person-centered Medicine from the area of prenatal screening is considered in more detail.
\end{abstract}

\section{Keywords}

FIGO, person-centered medicine, pre-natal diagnosis

\section{Correspondence Address}

Prof. Dr. Dr.h.c.mult. Wolfgang Holzgreve, Officer of the International Federation of Gynaecology and Obstetrics (FIGO) Wissenschaftskolleg zu Berlin, Institute for Advanced Study Wallotsrasse 19, D-14193 Berlin

Accepted for publication: 27 January 2011

\section{The Mission and organisation of FIGO}

The International Federation of Gynaecology and Obstetrics (FIGO) was founded in 1954 in Geneva and its ambition from the beginning was to bring together professional societies of obstetricians and gynaecologists on a global basis [1]. It grew from a federation representing 42 national societies into an international organisation with 110 national societies funded through subscriptions received from member societies, grants and the proceeds of its triennial World Congress. Lately, FIGO is more and more recognized almost as a NonGovernmental Organisation (NGO) and receives grants from major charity organisations such as for example the Bill and Melinda Gates Foundation for partnership programs in Africa and Asia. FIGO's mission is to promote the wellbeing of women and to raise the standards of practice in obstetrics and gynaecology around the world. The Executive Board is composed of representatives from twenty-four member associations and six Officers who, even though they were elected independently, come from five continents and are the following: Professor Gamal Serour (President: Egypt), Professor Takeshi Maruro (Vice President: Japan), Professor Sir Sabaratnam Arulkumaran (President-Elect: UK), Professor Dorothy Shaw (PastPresident: Canada), Professor Wolfgang Holzgreve (Honorary Treasurer: Switzerland/Germany), Ian Fraser (Honorary Secretary: Australia) and ex officio FIGO Chief Executive Professor Hamid Rushwan (Sudan/UK).The General Assembly of FIGO takes place every three years at the time of the triennial World Congress and is composed of delegates from each member association. FIGO is dedicated to the improvement of women's health and rights, to the reduction of disparities in healthcare available to women and newborns worldwide and to advancing the science and practice of obstetrics and gynaecology through advocacy, programmatic activities, capacity strengthening of member associations, education and training activities. One of the main tasks of FIGO is to help with promoting and achieving the so-called Millennium Development 
Goals by 2015, especially in the area of safe pregnancy, motherhood and newborn health. Furthermore, the commitment statement of FIGO lists as principal aims:

- Improving communication with and between member associations and building the capacities of those from low-resource countries through strengthening leadership, management, good practice and the promotion of policy dialogues.

- Strengthening capacities to enable societies to play a pivotal role in the development and implementation of sustainable programmes aimed at the improvement of care available to women and newborns, especially for poor and underserved populations.

- Recognising the importance of collaborative efforts for advancing women's health and rights, FIGO is committed to strengthening partnerships with other international professional organisations, UN agencies, and the public/private sector to achieve its objectives.

\section{The concept of person-centered medicine}

It has been pointed out that the broad and holistic understanding of medicine with roots both in Eastern (such as Chinese) and Western (particularly ancient Greek) traditions is already reflected in the encompassing definition of health inscribed in the constitution of the World Health Organization [2,3]. Recent initiatives have attempted to debate some developments of modern medicine such as conceptual reductionism, super specialization and fragmentation of service. The purpose of the International Network for Person-centered Medicine (INPCM) has been summarized as seeking "to articulate science and humanism in a balanced manner, engaging them at the service of the person"[2]. Since the INPCM activities include the formulation of person-centered clinical practice guidelines and of educational programs aimed at the training of health professionals on personcentered care as well as the conduction of studies and research projects to explore and validate person-centered care concepts and procedures, the following example from the area of prenatal diagnosis is intended to serve as an attempt to apply the principles to practice.

\section{Development towards a more person-centered medicine in prenatal screening for chromosomal abnormalities}

There is hardly any other time in the life of women with more joyful expectations and at the same time anxiety than during those months when they are pregnant and this can apply to whole families. Ever since human thinking and feelings were recorded, there has been concern that the child may develop normally in the uterus to have a good life after birth. Many surveillance practices are offered routinely during pregnancy, such as blood pressure, haemoglobin or urine assessments, and in the past women older than 35 years of age at the time of their pregnancy were told routinely that they would be at increased risk for children with numeric chromosome abnormalities, especially trisomy 21 , and therefore amniocentesis was offered to them to check for the chromosome count of the fetus. The reason that amniocentesis was not offered to all pregnant women mainly lies in the fact that it carries a procedure-related loss rate of the pregnancy of up to $1 \%$ $[4,5]$, and a recent meta-analysis on the complication rates of amniocentesis and chorionic villus sampling concluded: "Although the risks of pregnancy loss are relatively low, lack of adequate controls tends to underestimate the true added risk of prenatal invasive procedures" [6]. Because in the 1980 's only $5 \%$ of the pregnant women were older than 35 years old with this "Test-positive"-rate of 5\% around $20 \%$ of the cases with fetal Down's syndrome were detected, whereas $80 \%$ remained unrecognized. The main problem was that in a very "unpersonal" way, all women above the "magic" age of 35 were collectively and automatically put in the high risk category, so a more efficient and person-oriented way of assessing risk was searched for by medical investigators with the help of statisticians. First, biochemical markers such as $\alpha$ fetoprotein in the second trimester and later $\beta$-HCG and PAPP-A in the first trimester were recognised as showing characteristic changes in their average values in pregnancies with fetal trisomy 21. Ultimately, after validated algorithms became available, it was possible to detect 80 to $90 \%$ of all fetuses with trisomy 21 with the same test-positive rate of only $5 \%$ by taking maternal age, two biochemical measurements and one ultrasound marker, the so called nuchal translucency measurement as well as pregnancy dating by the measurement of the crown-rump length into account and this method is now robust with proper training and has been found to be highly reproducible in many countries [7]. Samples can be shipped and evaluation programs can be internet-based and so can be applied all around the world [8].

Many country guidelines now recommend that pregnant women should be offered information about screening methods and, if desired, an individual risk assessment for Down's syndrome in the first trimester based on a combination of the maternal age, nuchal translucency measurement and the biochemical markers mentioned above, so that they can be informed about their individual risk as odds, such as 1: 8000 or 1: 30 of carrying a fetus with Down's syndrome. This allows women with higher risk assessment to choose already in their first trimester chorionic villus sampling with its procedurerelated risk, whereas women with an individually low risk despite an age above 35 years find it easier to decide against an invasive procedure. So a much more person- 
and people-centered risk assessment has become possible and this development has, in fact diminished significantly the expected increase in the demand for invasive procedures to detect fetal trisomies based on the ever increasing average maternal age at the time of childbirth. For example, in the Federal Republic of Germany, the average age at the time of childbirth in 1970 was 23.8 years and increased to 27.8 in 2008 and in Switzerland even to 29.6 years of age [9]. In Germany, every $4^{\text {th }}$ child $(24 \%)$ is now born from a mother of more than 35 years of age. Between 1986 and 2008 the percentage of births in the age group 20 to 29 decreased from 64.5 to $42.5 \%$, whereas in the same time interval there were increases for the age groups 35 to 39 from 7.5 to 19 , between 40 and 44 from 1.1 to 4.8 and 45 and older from 0.08 to $0.2 \%$ [10].

Because of this very significant and continuing trend in demography towards higher ages of pregnant women and the clear correlation between maternal age and increased risk for chromosomal aneuploidies, one would have expected an increase in the demand for prenatal diagnostic procedures such as amniocentesis or chorionic villus sampling. This, however, did not happen, because it was influenced by the more person-centered new screening approaches mentioned above which allow for a much more individual risk assessment. This was confirmed in an impressive way by a population-based cohort study from Denmark conducted to evaluate the impact of the screening strategy introduced in that country during 2004 [11]. The results of this important study showed that while the number of children born with Down's syndrome decreased from 55-65 per year during 2000-4 to 31 in 2005 and 32 in 2006 , the total number of chorionic villus samplings and amniocenteses carried out also decreased from 7524 in 2000 to 3510 in 2006, with an increasing detection rate from $86 \%$ in 2005 to $93 \%$ in 2006 and a false positive rate of below 4\% in 2005-6. Therefore, the enormous development of multiple marker screening in early pregnancy has not only led to a much more individual, person-centered counselling practice and decision making by better informed women, but also to a considerable costsaving for society at large. To conclude, this example of progress towards more person-centered medicine in the area of prenatal medicine shows that a much more personal approach to screening is possible and that this can be accompanied by a long-term reduction in total costs for the health care system [12].

\section{Conclusion}

The trend for more person-oriented medicine has reached the area of obstetrics and gynecology which in itself covers a wide spectrum of sub-disciplines, from fetal-maternal medicine, obstetrics, benign gynecology, cancer medicine, endocrinology, reproductive medicine, urogynecology to psychosomatic medicine. The example discussed here from a development in prenatal diagnosis and screening shows that this more holistic approach which allows for better councelling and more individual evidence-based decision making by women is of benefit for persons seeking medical guidance as well as for society. The International Federation of Gynecology and Obstetrics therefore joins WHO and many sister organizations in supporting theconcept and practice and rapid development of Personcentered Medicine.

\section{References}

[1] Arulkumaran, S., Ludwig, H. (editors): The History of FIGO on the occasion of its $50^{\text {th }}$ anniversary, July 25-30, 2004. FIGO-book publication, London.

[2] Mezzich, J.E., Snaedal, J., Van Weel, C. \& Heath, I. Perspectives from the International Network for PersonCenterd Medicine. Opening remarks at the Third Geneva Conference on Person-Centerd Medicine, Geneva, May 35,2010 .

[3] World Health Organization: WHO Constitution. Geneva: WHO 1946.

[4] Golbus, M.S., Loughman, W.D., Epstein, C.J. et al.: (1979) Prenatal genetic diagnosis in 3000 amniocentesis. New England Journal of Medicine, 25, 157-163.

[5] Holzgreve, W., Miny, P. \& Gerlach, B. (1990) Benefits of placental biopsies for rapid karyotyping in the second and third trimester (late chorionic villus sampling) in highrisk pregnancies. American Journal of Obstetrics and Gynecology, 162, 1188-1192.

[6] Mujezinovic, F. \& Alfirevic, Z. (2007) Procedure related complications of amniocentesis and chorionic villous sampling: a systemic review. Obstetrics and Gynecology, 110, 687-694.

[7] Gasiorek-Wiens, A., Tercanli, S., Kozlowski,P. et al. (2001) Screening for trisomy 21 by fetal nuchal translucency and maternal age: a multicenter project in Germany, Austria and Switzerland. Ultrasound in Obstetrics and Gynecology, 18, 645-648.

[8] Holzgreve, W. (2007) Obstetrics in a globalized world. International Journal of Gynecology and Obstetrics,89, 203-204.

[9] Vienna Institute of Demography. International Institute for Applied Systems Analysis. European Demographic Data Sheet 2010.

[10] Ritzinger, P., Dudenhausen, J.W. \& Holzgreve, W. (2011) Late motherhood and its risks. Journal of Reproductive Medicine and Endocrinology, in press.

[11] Ekelund C.K., Jorgensen, F.S., Petersen, O.B., Sundberg, K. \& Tabor, A. (2008) Impact of a new national screening policy for Down's syndrome in Denmark: population based cohort study. British Medical Journal 337, 2547-2554.

[12] Hahn, S. \& Holzgreve, W. (2002) Prenatal diagnosis using fetal cells and cell-free fetal DNA in maternal blood: what is currently feasible? Clinical Obstetrics and Gynecology 45, 649-656. 